\title{
Pattern Recognition Using Time Statistic Classification
}

\author{
Rodolfo Romero Herrera \\ National Polytechnic Institute (ESCOM IPN) \\ México, D.F.
}

\section{Introduction}

A pattern recognition system should be composed of a sensor that gathers the observations to classify such a digital camera, a feature extraction system that transforms the information captured in numerical or symbolic, and a system of classification or description of the information measure.

A pattern recognition system must have a sensor in charged of getting the data to classify for example a digital camera, a characteristic collector system that changes the captured information to numeric or symbolic values, and a classification system of the measured information.

In this chapter we focus on the statistical classification. Its main classifier is based on probability theory. It is historically the first approach and that there was probably the most developed, but it does not mean that its development and research has been finished yet.

We begin with the moments used in statistics and which are basic, which can be used to find patterns within a data base by applying the statistical patterns in the recognition of particular facial expressions in digital video processing. Despite the good results that give us the recognition of patterns using the moment, these are not enough in many cases, so we need to use other mathematical operations such as correlation and covariance as well as other concepts derived from these equations.

Most of the processes studied have historically been analyzed in an instant of time, but I really did not occur in a second. Any experiment is deterministic; all have a degree of uncertainty. Researchers have developed a theory of probabilities, although again apply with respect to a viewpoint determistico. On why we must return to stochastic processes and add a clear perspective toward randomized experiments. Although there are many phenomena which can be applied the probability, we will focus on the affective computing, for the recognition of facial expressions, because it is a process that must be treated with this efoque. To accomplish this, first locate the face and then the characteristic points of the face; Once done, apply the statistical analysis with the expectation and variance in a process that varies in time, and therefore change these values. These functions can be characterized with Gaussian or Rayleigh. Although results are promising. It is evident that with increasing the number of stored data, requires more resources or more efficient implementation of algorithms for analysis and interpretation of data. 


\section{Procedures for classification of patterns}

The statistical approach extracts quantitative properties. The syntactic approach is based on relations associated with the geometric shape of objects. objects and the appearance-based approach considers ways to view them(Gonzalez, 2002).There are many applications of statistical pattern recognition such as finite state machine translation (Vincent alabu, 2007). Statistical pattern recognition is characterized by the use of vectors for the representation of patterns $(x 1 \ldots x n) € R n$, while the arrangement or, more generally, graphs are attacked in structural recognition. The recognition process is based on assuming that the patterns of the same class are located in a compact region $\mathrm{Rn}$. The representation of objects given in terms of the vector has several properties such as the similarity of objects or Euclidean dintancia (Kaspar Reisen).

\section{Statistical classification}

Many new applications for developing models from data have been inspired by the capabilities of biological systems, particularly in the human biological system. Indeed, biological systems learn to accommodate the statistical nature of the environment. Both humans and animals have excess capacity on the recognition of faces, voices or smells but learn through interaction with the environment. The pattern recognition systems are based on the principles of engineering and statistics rather than on biology, however, there is an attempt to imitate the human brain or animal (Gonzalez 2002).

\section{Moments}

\subsection{Probability density function}

Much of the Japanese success is due to the use of statistical methods, which implies a large collection of information or scientific data. However, there is a big difference between collecting scientific information and inferential statistics. The use of techniques that allow us to move beyond data support; rather we infer conclusions. The information is collected as samples or groups of observations. Samples are collected from populations, which are groupings of all individuals or individual elements of a particular type. Obtaining these data is an experiment; therefore it must be repeatable and conclusions as well, however just a small change to the data change; but, in the statistical analysis, despite this small change the conclusion remains.

\subsection{Random Variables}

Suppose that each point in space we assign a sample number. Then we have a defined role in the sample, called stochastic variable or stochastic function. It is usually denoted by a capital letter, like $\mathrm{X}$ or $\mathrm{Y}$. A random variable that takes a finite number of values is called discrete random variable, while one that takes an infinite number of values not accounting is called a random variable not discrete (Murray, 2001).

$\mathrm{X}$ is a discrete random variable, and suppose that the possible values that it can have are given by $x 1, x 2, x 3, \ldots$. , with certain order. Assume further that these values are taken with probabilities given by: 


$$
\mathrm{P}\left(\mathrm{X}=\mathrm{x}_{\mathrm{k}}\right)=\mathrm{f}\left(\mathrm{x}_{\mathrm{k}}\right) \quad k=1,2, \ldots \ldots
$$

Then the probability distribution is given by:

$$
P(X=x)=f(x)
$$

For $x=x_{k}$, is reduced to the equation (1), while for other values of $x, f(x)=0$.

In general, $\mathrm{f}(\mathrm{x})$ is a probability function if

$$
f(x) \geq 0
$$

$$
\sum_{x} f(x)=1
$$

\subsection{Dimensional distribution}

Consider two discrete random variables, we define the joint probability function of $X$ and $Y$ given by:

Where:

$$
P(X=x, Y=y)=f(x, y)
$$

$$
f(x, y) \geq 0
$$

$$
\sum_{x} \sum_{y} f(x, y)=1
$$

That is to say, the sum of all values is equal to one $\mathrm{X} y \mathrm{Y}$.

Equation 7 gives us the most complete information about a two-dimensional random variable.

Suppose that $X$ can assume any of the $m$ values $x_{1}, x_{2}, x_{3}, \ldots \ldots x_{m}$ and $Y$ can take any of the values $y_{1}, y_{2}, y_{3} \ldots . ., y_{n}$. Then the probability of event $X=Y=x_{j}$ and $y_{k}$ is given by

$$
P\left(X=x_{j}, Y=y_{k}\right)=f\left(x_{j}, y_{k}\right)
$$

If we want the distribution of probability for each cardinal separately, it is clear that the probability of $y_{k}$ must add all possible values in $x_{j}$

$$
P\left(y_{k}\right)=\sum_{j} P\left(x_{j}, y_{k}\right)
$$

Similarly:

$$
P\left(x_{j}\right)=\sum_{k} P\left(x_{k}, y_{j}\right)
$$

In many situations the two random variables $X$ and $Y$, taken together, are a very natural result of a single experiment (L Paul). 


\section{Mathematical expectation}

Moments are called the "expectation of some important types of functions. The Mathematical expectation is defined as (Elmer, 2005):

$$
<x>=\sum x_{i} P\left(x_{i}\right)
$$

Considering the multitude of central moments, That is to say, moments with respect to base, we have that:

$$
<\dot{x}^{n}>=\sum\left(x_{i-}<x>\right)^{n} P\left(x_{i}\right)
$$

The second central moment is then defined as:

$$
<\dot{x}^{2}>=\sum\left(x_{i-}<x>\right)^{2} P\left(x_{i}\right)
$$

An analysis of the second central moment, this results in increased when the distance of possible values increases and the mathematical expectation increases. Then we can conclude that him second central moment evaluates the dispersion of the possible values with respect to the mathematical expectation, it is called the variance $\sigma^{2}$. The standard deviation is defined as $\sigma=\sqrt{\sigma^{2}}$. The deterministic variables do not have standard deviation; that is to say:

$\sigma 2$ of constant $=0$

In the case of a bidimensional random variable is twice the initial and central moments with respect to the unidimensional random variable, and it is possible to introduce mutual initial and central moments:

$$
\begin{aligned}
& <x^{n} y^{y}>=\iint x^{n} y^{n} f(x, y) d x d y \\
& <\dot{x}^{n} \dot{y}^{n}>=\iint \dot{x}^{n} \dot{y}^{n} f(x, y) d x d y
\end{aligned}
$$

\section{Relations in the random variables}

\section{$x, y$ are independent}

Means that the result of the experiment a random variable does not influence the experiment of another random variable.

If

but are independent, then:

$$
P(A B)=P(A) P(B \mid A)
$$

$$
\mathrm{P}(\mathrm{AB})=\mathrm{P}(\mathrm{A}) \mathrm{P}(\mathrm{B})
$$




\section{Functional dependence}

The result of an experiment of a random variable affecting the likelihood of the values of another variable.

\section{Statistical dependency}

This result should be a measurement mathematics which can be evaluated and that is within the mutual moments.

\section{Moment of Covariance}

We propose $\langle\dot{x} y\rangle \square$ with $\mathrm{n}=\mathrm{m}=1$

Case $1 \mathrm{x}$ and $\mathrm{y}$ are independent

In the continuous case we have:

$$
<\dot{x} \dot{y}>=\int \dot{x} \dot{y} f(x, y) d x d y
$$

We must:

$\mathrm{P}(\mathrm{AB})=\mathrm{P}(\mathrm{A}) \mathrm{P}(\mathrm{BIA})$ as similarly $f(x, y)=f(x) f(y I x)$

But $x$ and $y$ are independent so that: $f(x, y)=f(x) f(y)$

Substituting in the formula ()

$$
<\dot{x} \dot{y}>=\int \dot{x} f(x) d x \int \dot{y} f(y) d y=0
$$

Because the expectation of the first moment is zero by definition.

\section{Case 2 dependence.}

We propose $\mathrm{y}=\mathrm{kx}+\mathrm{a}$

Where " $k$ " and "a" are constants

Let us now consider a discrete case.

$$
<\dot{x} \dot{y}>=\sum_{i} \sum_{j} \dot{x}_{i} \dot{y}_{j} P\left(x_{i}\right) P\left(x_{i}\right) P\left(y_{i} \mid x_{i}\right)
$$

Of equation (20) we will analyze:

Because it is a line we must:

$$
\sum \dot{y}_{j} P\left(y_{j} \mid x_{i}\right)
$$

$$
P\left(y_{j} \mid x_{i}\right)= \begin{cases}0 & j \neq i \\ 1 & j=1\end{cases}
$$

Therefore the equation (21) is equal to $\dot{y}_{j}$

Substituting into (20) we have

$$
<\dot{x} \dot{y}>=\sum_{i} \dot{x}_{i} \dot{y}_{j} P\left(x_{i}\right)
$$


On the other hand we have:

$$
\begin{gathered}
\dot{y}=y-<y> \\
<y>=<k x+a>=<k x>+<a>=k<x>+a
\end{gathered}
$$

Substituting in (24)

$$
\sum \dot{x}_{i} \dot{y}_{j} P(x)=\sum \dot{x}_{i} k \dot{x}_{i} P\left(x_{i}\right)=k \sum \dot{x}_{i}^{2} P\left(x_{i}\right)=k \sigma_{x}^{2}=<\dot{x} \dot{y}>
$$

Therefore we have:

$$
0 \leq<\dot{x} \dot{y} \leq k \sigma_{x}^{2}
$$

\section{Random process}

When we have many achievements and chose a time $\mathrm{t} 1$, in this section we have many points which are traces of each realization. that is to say, in this section we have a variate, this variate depends on the phase. See Figure 1. To have multiple signals and therefore data, while it is very difficult to describe analytically through each realization and their probabilities. Meaning that, we must determine a number for each function of time; this number is known as functional. However, there are few processes which are known for their function

We will try to describe our random process with a lot of $\mathrm{f}(\mathrm{p})$-dimensional.

\section{The function mathematical expectation and the covariance function}

There is a section of time and a one-dimensional random variable $x i$, so you can get a lot of initial and central moments of any order, thus producing the mathematical expectation for each section. Join these points and we obtain a deterministic function(Romero, 2005). It is possible to calculate for each section, many high-order moment and again unite the charts. For example, you can calculate its variance for each section. This function is called the function of the variance of our random process. 


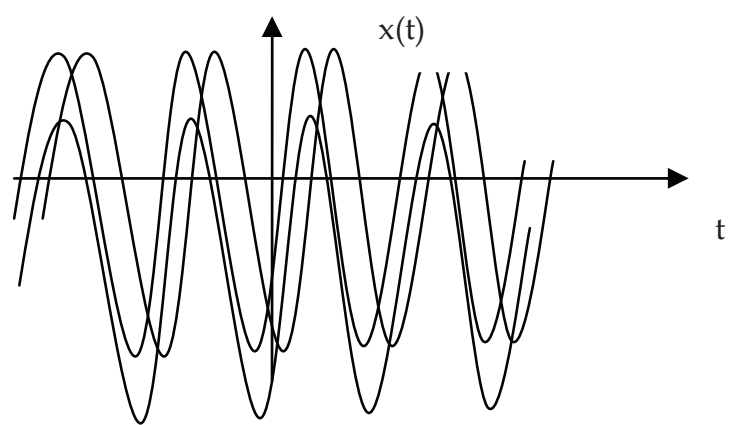

Fig.1. Functions of a complex process aletorio

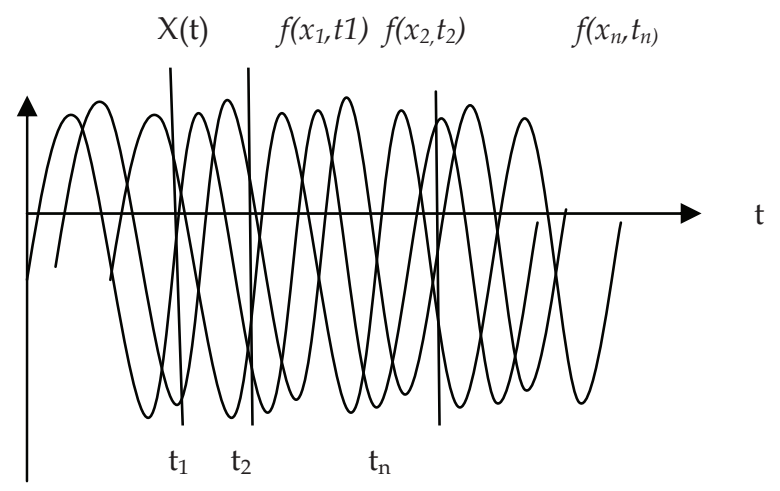

Fig. 2 Segmentation of random process

The processes may have the same function of mathematical expectation and of variance; however these processes may be different, reason why the functions moment of first order are not sufficient. Because they do not find the difference within the structure of two-time random processes different. it is by this, that considers the bidimensional variates; for example at the time t1tenemos the random variable $X_{1}\left(t_{1}\right)$ and at the time $t_{2}$ we have the random variable $\mathrm{X}_{2}\left(\mathrm{t}_{2}\right)$. These two random variables forming a two dimensional random variable. Each two-dimensional random variable can be described with two-dimensional function $\mathrm{f}\left(\mathrm{X}_{1}\left(\mathrm{t}_{1}\right), \mathrm{X}_{2}\left(\mathrm{t}_{2}\right)\right)$. Can be calculated many mutual initial and central moments of any order. We chose the momnet $\left\langle\dot{X}_{1}\left(t_{1}\right) \dot{X}_{2}\left(t_{2}\right)\right\rangle$, which we know as the moment covariate. This moment is a number deterministic and evaluates the statistical dependence between two linear sections in the random process. This moment is called a covariance function.

$$
K x\left(t_{1}, t_{2}\right)=<\dot{X}_{1}\left(t_{1}\right) \dot{X}_{2}\left(t_{2}\right)>\left.\right|_{t_{2} \rightarrow t_{1}}=<\dot{X}_{1}^{2}\left(t_{1}\right)>=\sigma_{x}^{2}\left(t_{1}\right)
$$

Where this result is the maximum of the covariance function, where there is total dependence. When we increase the distance between two sections, the covariance function tends to zero. So if a process is smooth covariance function tends to zero slowly, if the 
process is very chaotic then the covariance function tends to zero too fast, that is to say, that the covariance function reflects the difference between the structures of the time in the random processes.

\section{Stationary Random Process}

The random process is called stationary when its mathematical hope does not depend on the time, its variance does not depend on the time and its function of covariance does not depend on its section fixes (time) and only depends on the distance between two sections $(\tau)$.

Here it is important to note that the covariance function is equal to the variance when the distance $\tau$ is equal zero, this means that the function of covariance includes information about the variance.

When two random processes $X(t)$ y $Y(t)$ are different, but have statistical dependence, then we characterize the role of mutual covariance with the expression:

$$
<\dot{x}(t) \dot{y}(y+\tau)=K_{x y}(\tau)=\iint \dot{x}(t) \dot{y}(t+\tau) f(x(t), y(t+\tau) d x(t) d y(t+\tau)
$$

If the function compares with itself with retardation we have:

$$
K_{x}(\tau)=<\dot{x}(t) x(t+\dot{\sigma})>
$$

Which is called autocovarianza function.

There are other moments in the initial and central base dimensional but it's very complicated to calculate; however when the process is Gaussian, is sufficient to characterize $K_{x}$ ( $\left.t 2-t 1\right)$. So if you find that the process is Gaussian then simply calculate the value of a parameter for $\mathrm{K}_{\mathrm{x}}$ for learning.

\section{Method Viola \& Jones.}

In this application, first use a technique for locating the face, with the purpose of applying statistical methods. There are many different techniques for the detection and location of the face in an image, each one whit special characteristics. Most of the techniques have problems such the detection of a high number of false positives with no uniform background or a time high in the analysis of the image, because by nature of the project is essential image processing time Real is considered a technical proposal by Paul Viola and Michael J. Jones, with which the faces are detected at a speed of 24 frames per second tested in a conventional machine with an Intel Core Duo 1.8 Ghz.

This method is basically the location of the face using a group of rectangular features which are seeking a set of features a combination of clear parts and dark rectangles distributed within the face (Viola \& Jones, 2001 ).

The main reason for using these features rectangular is that a system based on characteristics operates faster than a system based on pixels

We use three kinds of characteristics: the two rectangles, three rectangles and four rectangles. These features rectangular (CRs) are 10 different types shown in Figure 3 


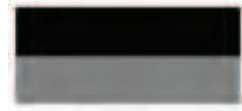

Type 1

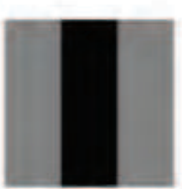

Type 5

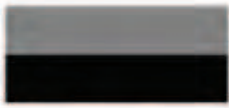

Type 2

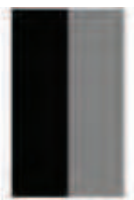

Type 3

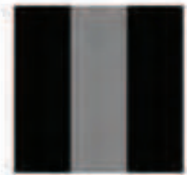

Type 6

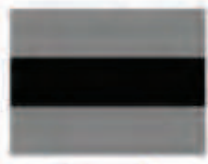

Type 7

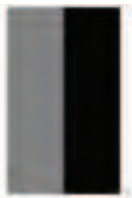

Type 4

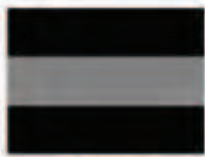

Type 8

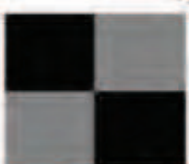

Type 9

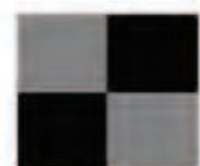

Trpe 10

Fig. 3. Set of ten rectangular features used in the process of locating faces

The ways to use these CRs, is placing them in a certain position within the image and calculate the difference between the amounts of pixels within the clear part the dark side of the $\mathrm{CR}$, gaining an integer value that it must overcome a certain threshold to be considered as being on the facial feature that should locate. This phase of training is to find the CRs that in a certain scale and position within a window of size $142 * 116$ pixels, as well as its threshold, can pinpoint a feature of a human face, and this CR receives name classifier.

In Figure 4 you can appreciate a package of 16 classifiers where all classifiers figure locate a feature of the face.
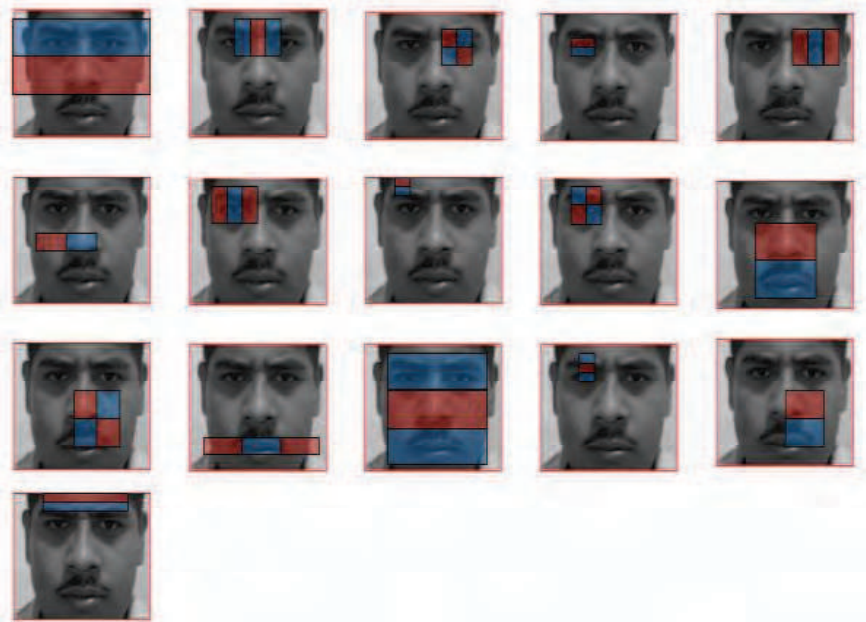

Fig. 4.- 16 rectangular features.

Once you have all these classifiers with their thresholds are placed cascading to expedite the processing power and do it in real time. Each waterfall has a number $\mathrm{n}$ binder and has a 
total of $\mathrm{m}$ levels of the waterfall. The more levels of the waterfall will take more processing time.

To calculate the CRs very quickly at various scales using a representation of the image called comprehensive picture. The comprehensive picture can be calculated with a couple of operations per pixel. Once calculated, any of the CRs can be calculated at any scale and location in a time constant. The image in a comprehensive position $(x, y)$ contains the sum of the pixels above and left of $(x, y)$, including it.

$$
i i(x, y)=\sum_{x^{\prime} \leq x, y^{\prime} \leq y} i\left(x^{\prime}, y^{\prime}\right)
$$

Where ii $(x, y)$ is the holistic picture yi $(x, y)$ is the original image (Figure 4). Using the next couple of recurrences:

$$
\begin{aligned}
& \text { s }(x, y)=s(x, y-1)+\text { i }(x, y) \\
& \text { ii }(x, y)=\text { ii }(x-1, y)+s(x, y)
\end{aligned}
$$

Where $s(x, y)$ is the cumulative sum of the values of the pixels of the row, $s(x-1)=0$, and ii $(-1, y)=0)$ the integral image can be calculated in one pass on the original image [7].

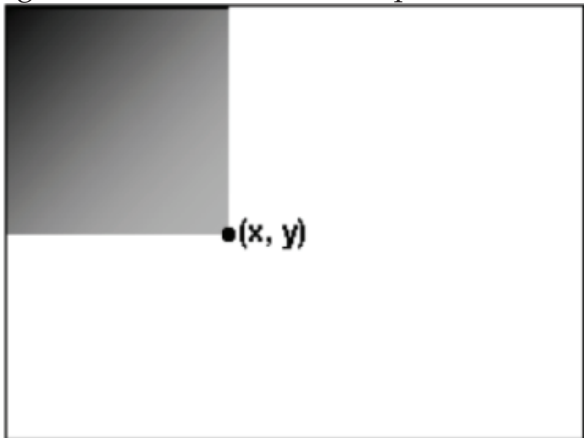

Fig. 5 .- The value of a comprehensive picture at one point $(x, y)$ is the sum of all pixels up and left

In Figure 6 the red rectangle shows the position in which the system has made the location of the face with a size of $142 * 116$ pixels. 


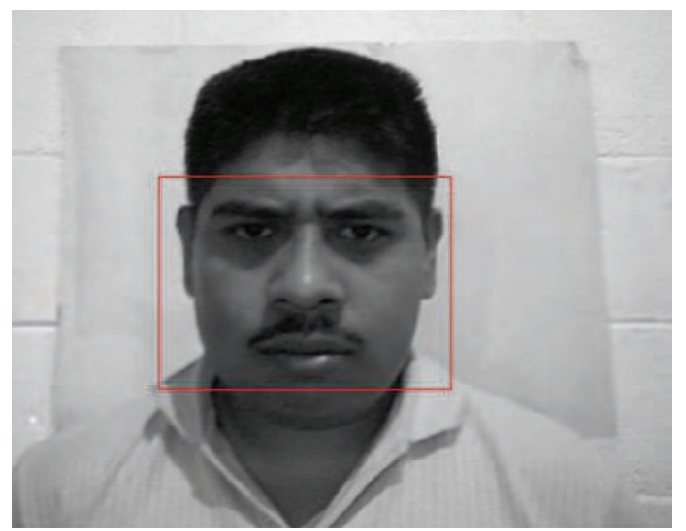

Fig. 6.- Detector of the face

\section{The operator Nitzberg}

Nitzberg proposes an operator making it possible to estimate the magnitude of the gradient and its orientation, as well as evidence of the presence of points corner. It uses the information in the gradient at a particular neighbourhood and combines it with a gradient operator to reduce noise. The first thing that is done is to calculate the partial derivatives in $x$ and $y$ throughout the image (Nitzberg \& Shiota, 1993):

$$
\begin{aligned}
& I_{x}(x, y)=\frac{I(x+1, y)-I(x-1, y)}{2} \\
& I_{y}(x, y)=(I(x, y+1)-I(x, y-1)) / 2
\end{aligned}
$$

Here is defined as follows $2 \times 2$ matrix:

$$
Q(x)=\int d x^{\prime} \rho\left(x-x^{\prime}\right) \nabla I\left(x^{\prime}\right)^{T}=\int d x^{\prime} \rho\left(x-x^{\prime}\right)\left(\begin{array}{cc}
I_{x}^{2}\left(x^{\prime}\right) & I_{x} I_{y}\left(x^{\prime}\right) \\
I_{x} I_{y}\left(x^{\prime}\right) & I_{y}^{2}\left(x^{\prime}\right)
\end{array}\right)
$$

where $\nabla I(x)$ is a vector column and $\rho(x)$ is a function of decreasing weight with maximum value is 0 .

The matrix $Q(x)$ have an auto-value associated with the $\lambda_{1}(x)$, associated to the auto-vector $e_{1}(x)$ and a ato-value minor $\lambda_{2}(x)$. magnitude of the self-vector is give for $I_{e}(x)=\lambda_{1}(x)$ and them orientation for the orientation of a auto-vector associated $\theta_{\mathrm{I}}(\mathrm{x})=e 1(\mathrm{x})$ direction of selfassociated vector calculation fot of points corner is used the value of the second self-worth or self-worth less than $I_{c}(x)=\lambda_{2}(x)$.

The role of weighting $\rho(x)$ allows us to soften to a greater or lesser $\rho$ The role of weighting extent. In the experiments, and for simplicity, we selected the following function : 


$$
\rho(x)=\left\{\begin{array}{lr}
\frac{1}{w^{2}} & -\frac{w}{2} \leq x \frac{w}{2} y-\frac{w}{2} \leq y \leq \frac{w}{2} \\
0, & \text { in other case }
\end{array}\right.
$$

This descriptor contour allowed analyse frames taken by a video capture system, which provides the result is a frame that represents the pixels characteristic of it. [10].

It is an estimate of the location of the eyes, nose and the mouth which applies the operator Nitzberg this helps only get the information most important Figure 7.

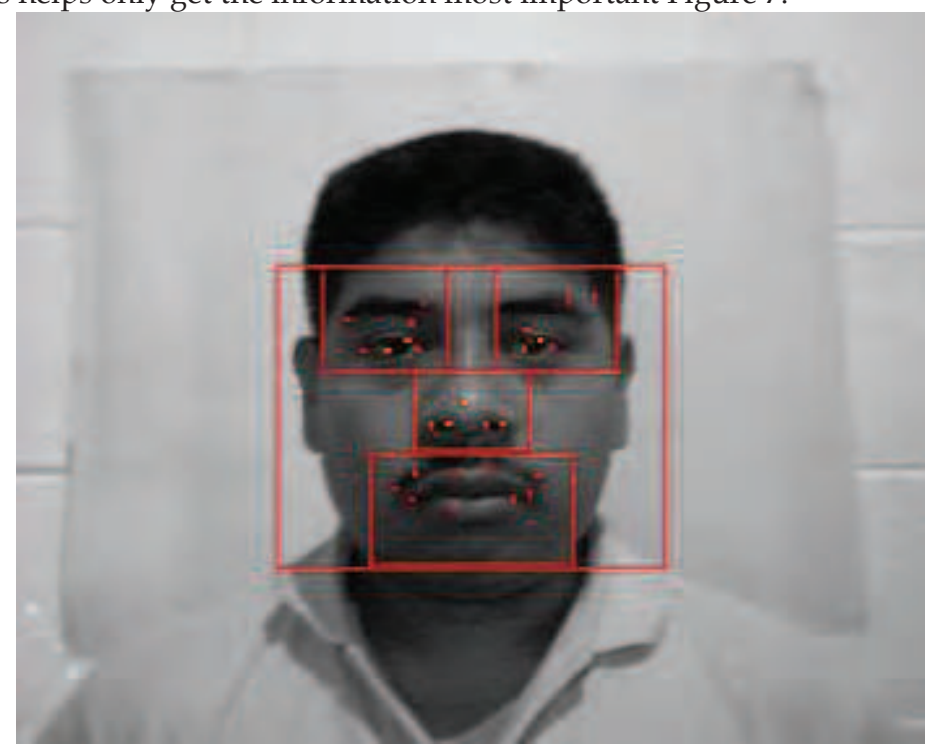

Fig. 7. Implementation of the operator Nitzberg

\section{Applications.}

To apply the reasoning, we obtained graphs of a system for detecting bodily emotions, and other of recognition of facial expressions, and a simulation system that uses emotional states "Cathexis" (Velazquez, 1996).

The graphs are shown in Figures 8, 9; Show the behavior of the recognition of bodily expression. The mathematical expectation shows curves similar to Gauss and Rayleigh. 


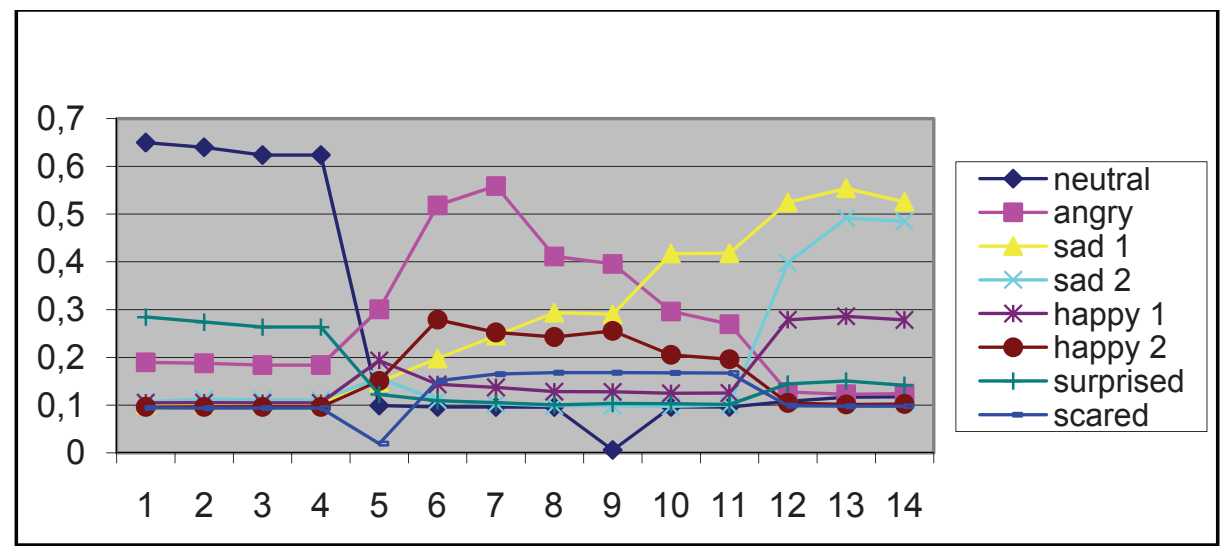

Fig. 8 Expectation of recognition of bodily expressions

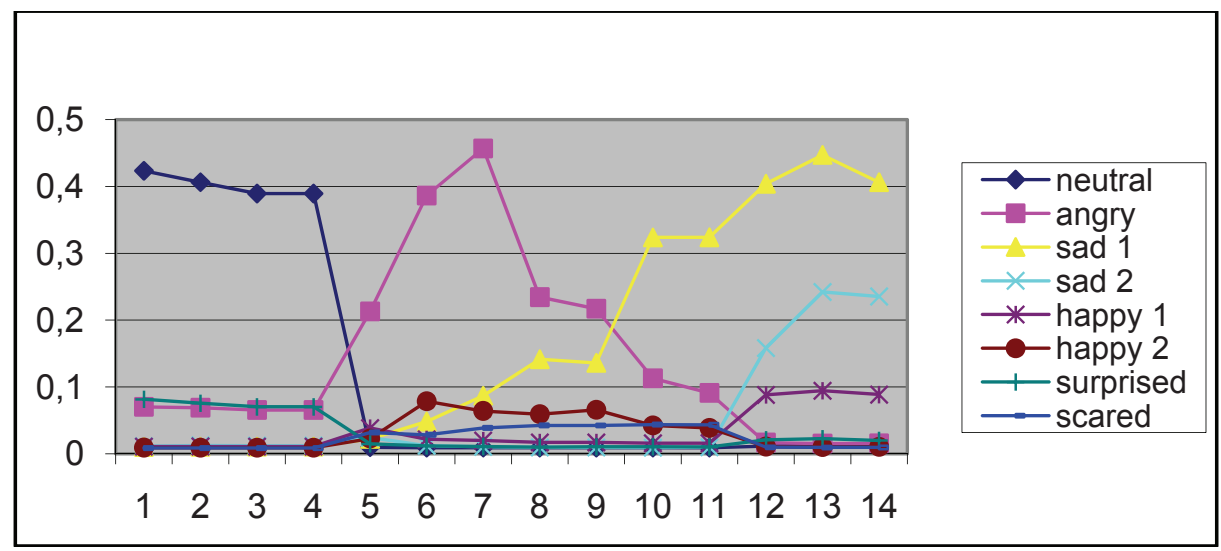

Fig. 9 Variance for the recognition of bodily expressions

In Figure 10 and 11 shows the result of recognition of facial expressions and again shows that the expectation tends to be Rayleigh or Gaussian 


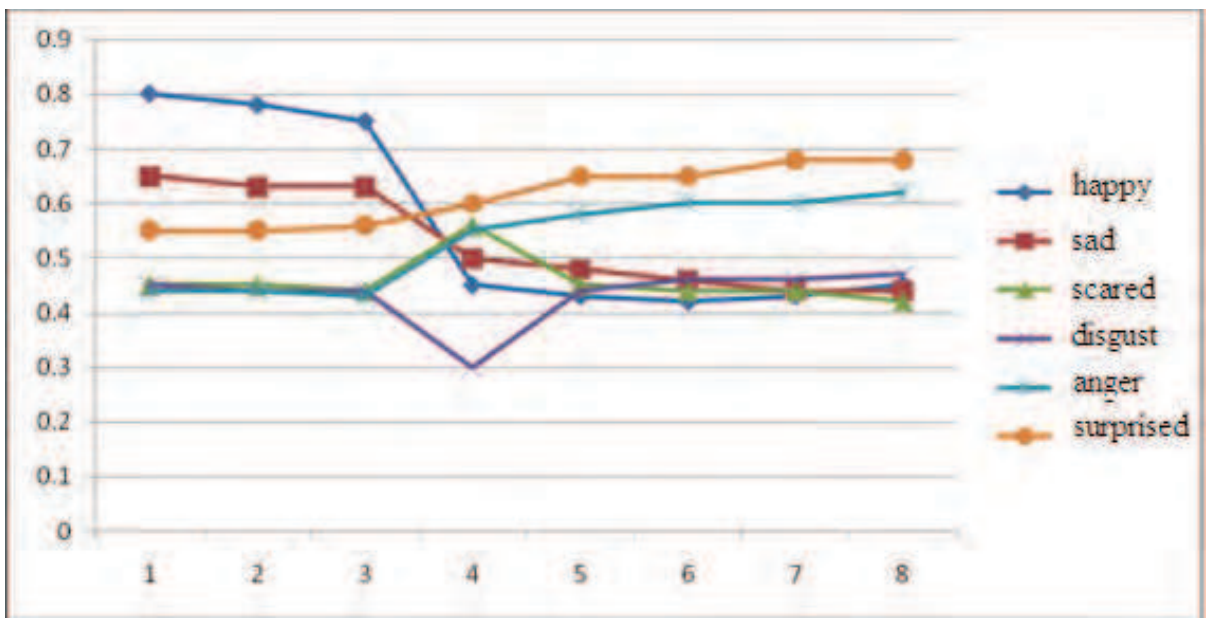

Fig. 10. Expectation for the recognition of facial expressions

For the simulation is used ecuasion of cathexis (Velazquez, 1996). The result is the same Gaussian behavior.

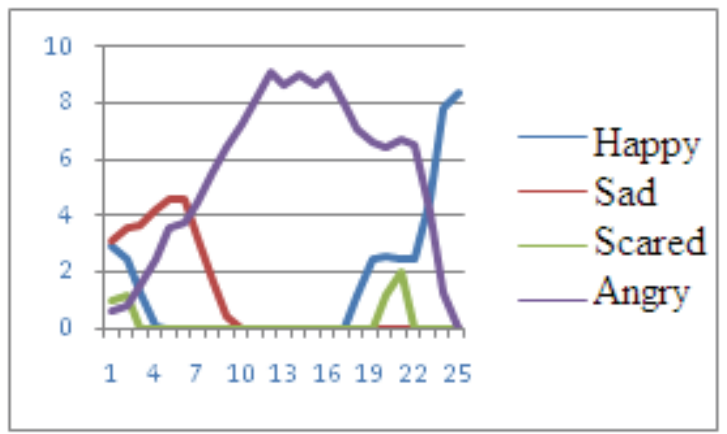

Fig. 11. Mathematical Expectation for the simulation of cathexis.

Influence emotional behavior among themselves, thus changing the graphic Gaussian perfect, and for this very reason also has a tendency to Rayleigh curves. Gaussian function is defined by the equation (Osborn 2007) (Van 2008):

$$
f(x)=a e^{-(x-b)^{2} / 2 c^{2}}
$$

Where $a, b$ and $c$ are real constants ( $>0$ ). The graph of the function is symmetrical bellshaped. The parameter " $a$ " is the height of the campaign centered on the point $b$, determining the width $C$ of the same. For this particular case $f(x)$ is the expectation for figures 1,3 and 4 . If the case of Figure $4 \mathrm{f}(\mathrm{x})$ is the variance.

The function is defined by the Rayleigh equation (Vanek \& Albright, 2008) (Kalimuthu, 2006): 


$$
f(x \mid \alpha)=\frac{x e^{\frac{-x^{2}}{2 \alpha^{2}}}}{\alpha^{2}}
$$

Where $a$ is the height of the graphs of Rayleigh and therefore the parameter of interest. Therefore if the system takes the parameter a or the maximum height, we can store this information and if the value is repeated with a certain tolerance of it as part of learning within a knowledge base. In probability theory and statistics, the Rayleigh distribution is a continuous distribution function. When a file is usually two-dimensional vector has two components, orthogonal and independent and follow a normal distribution. That is where Rxx tends to zero.

Therefore, the value of Kxx does not help to determine whether a Gaussian or Rayleigh. That is, if $\mathrm{Kxx}$ tends to 1 then it is a Gaussian function with a linear dependence.

\section{Conclusion}

There are many phenomena whose processes are not significant, practically everything in nature. It is essential for this in-depth analysis and generation of methods that take into account the random processes, and within those involving such time as a variable (stochastic processes). We present a method that is efficient for learning commands, based on the recognition of emotional expressions. The correlation was not a measure to infer whether it was random or a linear dependence, and on this basis to determine the possible plot to use. The processing time depends on how successful it is to be learning. It is clear that more data are obtained will be more efficient learning, but as long as it learns to be a higher order.

The effectiveness of the methodology was tested in a simulation, it would need to use a robot for example, or industrial machines, but the results promise good projection Asia all stochastic processes with Gaussian or Rayleigh graphs. The implementation of the system within a robot is part of future work, as well as implements inference techniques.

\section{References}

Vicente Alabu, Francisco Casacuberta, Enrique Vidal, Alfons Jua (2007) Inference of stochastic Finite-state Traducers Using N Gram mixture; Pattern recognition and Image Analisys; Thrid Iberian Conference, Proceedings part IILNCS 4478; Springer Girona Spain

Kaspar Reisen, Michel Neuhaus, Horst Bunke (2007) Graph Embedding in vector spaces by means of prototype selection ; Graph Based Representations in Pattern recognition; $6^{\text {th }}$ IAPR -TC-15 International Workshop, GbRPR Proceedings; LNCS 4538, Springer , Alicante Spain.

González Pajares, Jesús M. de la Cruz (2002) Visión por computador Imágenes digitales y aplicaciones; Alfaomega Ra-Ma; pp. 373-418; México D.F; ISBN 970-15-0804-1;

Murray R. Spiegel, John Schiller, R. Alu Srinivasan (2001) Probabilidad y estadística; Mc Graw Hill, Colombia, ISBN: 958-41-0133-1

Elmer B. Mode, R. García Garza (2005). Elementos de probabilidad y esatadística, Reverte, ISBN: 8429150927, Barcelona

Romero Villafranca Rafael, Zunica Ramajo Luisa Rosa (2005). Métodos estadisticos en Ingeniería ;Ed. Univ. Politecnica de valencai ; 334 pp ; ISBN : 849705279 ; Spain. 
Viola, Paul \& Jones, Michael (2001) Robust Real-Time Object Detection, International Journal of Computer Vision, 57, 2, December 2004, 137-154, ISSN: 0920-5691 (Print) 1573-1405 (Online Siegwart, R. (2001). Name of paper. Name of Journal in Italics, Vol., No., (month and year of the edition) page numbers (first-last), ISSN

Nitzberg M., DMumford, TShiota (1993) Filtering, Segmentation, and Depth, SpringerVerlag New York, Inc, 143pg, ISBN: 3540564845, USA

Velásquez J D.. (1996)“Cathexis: a computational model for the generation of emotions and their influence in the behavior of autonomous agents". S. M. Thesis. Department of electrical engineering and computer science, Massachusetts institute of technology, 1996.

Osborn Carol E.(2007) Basic Statistics for Health Information Management Technology; Jones \& Bartlett Publishers, ISBN: 0763750344, 9780763750343; USA

Van Vliet Caroyne M.(2008) Equilibrium and Non-Equilibrium Statistical Mechanics; World Scientific, ; ISBN: 9812704779, 9789812704771; USA, UK

Vanek Francis M., Albright Louis D.(2008) Energy Systems Engineering: Evaluation and Implementation; McGraw-Hill Professional, ISBN: 0071495932, 9780071495936; USA

Kalimuthu Krishnamoorthy(2006) Handbook of statistical distributions with applications; CRC Press; ISBN: 1584886358, 9781584886358; USA 


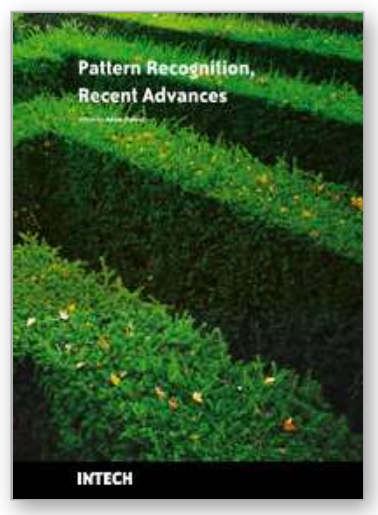

\section{Pattern Recognition Recent Advances}

Edited by Adam Herout

ISBN 978-953-7619-90-9

Hard cover, 524 pages

Publisher InTech

Published online 01, February, 2010

Published in print edition February, 2010

Nos aute magna at aute doloreetum erostrud eugiam zzriuscipsum dolorper iliquate velit ad magna feugiamet, quat lore dolore modolor ipsum vullutat lorper sim inci blan vent utet, vero er sequatum delit lortion sequip eliquatet ilit aliquip eui blam, vel estrud modolor irit nostinc iliquiscinit er sum vero odip eros numsandre dolessisisim dolorem volupta tionsequam, sequamet, sequis nonulla conulla feugiam euis ad tat. Igna feugiam et ametuercil enim dolore commy numsandiam, sed te con hendit iuscidunt wis nonse volenis molorer suscip er illan essit ea feugue do dunt utetum vercili quamcon ver sequat utem zzriure modiat. Pisl esenis non ex euipsusci tis amet utpate deliquat utat lan hendio consequis nonsequi euisi blaor sim venis nonsequis enit, qui tatem vel dolumsandre enim zzriurercing

\section{How to reference}

In order to correctly reference this scholarly work, feel free to copy and paste the following:

Rodolfo Romero Herrera (2010). Pattern Recognition Using Time Statistic Classification, Pattern Recognition Recent Advances, Adam Herout (Ed.), ISBN: 978-953-7619-90-9, InTech, Available from: http://www.intechopen.com/books/pattern-recognition-recent-advances/pattern-recognition-using-time-statisticclassification

\section{INTECH}

open science | open minds

\section{InTech Europe}

University Campus STeP Ri Slavka Krautzeka 83/A

51000 Rijeka, Croatia Phone: +385 (51) 770447

Fax: +385 (51) 686166

www.intechopen.com

\section{InTech China}

Unit 405, Office Block, Hotel Equatorial Shanghai

No.65, Yan An Road (West), Shanghai, 200040, China

中国上海市延安西路65号上海国际贵都大饭店办公楼405单元

Phone: +86-21-62489820

Fax: +86-21-62489821 
(C) 2010 The Author(s). Licensee IntechOpen. This chapter is distributed under the terms of the Creative Commons Attribution-NonCommercialShareAlike-3.0 License, which permits use, distribution and reproduction for non-commercial purposes, provided the original is properly cited and derivative works building on this content are distributed under the same license. 